\title{
Reseña de La Rampa de Pajares
}

\author{
Review of La Rampa de Pajares
}

Lorenzo López Trigal $^{1}$

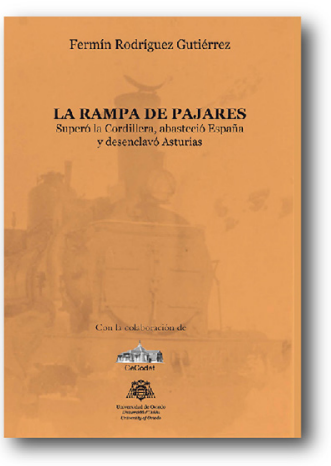

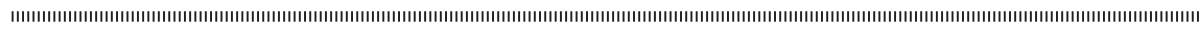

Autor: Rodríguez Gutiérrez, F.

Título: La Rampa de Pajares. Superó la Cordillera, abasteció España $y$ desenclavó Asturias

Año: 2018

Ciudad: Oviedo

Editorial: Ediciones de la Universidad de Oviedo

Páginas: $197 \mathrm{pp}$.

ISBN: 978-84-16343-75-1
La visión del transporte ferroviario ha sido casi excepcional entre los geógrafos españoles, como pudimos comprobar con ocasión de la Reunión del Grupo de Trabajo 'Geografía del Transporte' de la UGI, celebrada en León en agosto de 1986, al amparo de la Conferencia Regional sobre Países Mediterráneos. Si bien se contaba ya con trabajos pioneros de tipo teórico, como el desarrollado en la Universidad de Barcelona — denominado Equipo Urbano y dirigido por Horacio Capel-, que aplica el modelo de simulación a la red ferroviaria española (Revista de Geografía, 1972), o con algunas monografías de estudio sobre Los Accesos ferroviarios a Madrid (María Pilar González Yanci, 1977), Los Ferrocarriles del Sureste (Antonio Abellán García, 1979) y, posteriormente, siguen, entre otras, alguna Tesis doctoral como El Transporte de viajeros por ferrocarril en la Comunidad Autónoma de Madrid (Gloria Fernández-Mayoralas, 1988), que se complementan con estudios sobre los ferrocarriles de vía estrecha o más recientemente sobre la Alta Velocidad ferroviaria y sus efectos.

Abellán proponía en su estudio un esquema de trabajo sobre el ferrocarril a partir del estudio de los factores condicionantes de la construcción de líneas, la historia de las concesiones ferroviarias y los proyectos de líneas, el análisis cuantitativo de los tráficos, el análisis cualitativo del transporte de mercancías, la rentabilidad y el cierre problemático de líneas, las características de los viajeros y, por último, la estación ferroviaria y su papel en el crecimiento urbano y en la localización industrial. En buena medida, los estudios geográficos posteriores se han aproximado a estas temáticas.

La obra del profesor Fermín Rodríguez supone una contribución a varias de estas líneas de trabajo y viene a ser un relato de la infraestructura ferroviaria de mayor relieve de la red de ancho ibérico, de sus prolegómenos y de sus avatares desde que se inaugurase el último tramo intermedio en 1884 , dando servicio a la comunicación de viajeros y correo así como al transporte de carbones y diferentes productos entre Asturias y León. El subtítulo de la obra delata la importancia de su obra y cometidos: "superar la Cordillera Cantábrica, abastecer a España y desenclavar a Asturias". Veamos, en este mismo orden, la temática tratada.

En primer término, fue una obra de extrema complejidad en su construcción y lo sigue siendo en su mantenimiento, propia de un tramo de $42 \mathrm{ki}-$

1 Departamento de Geografía y Geología, Universidad de León, España. 1.trigal@unileon.es 
lómetros de montaña entre Busdongo y Puente de los Fierros, que se considera como rampa, por la dificultad de superar pendientes en túneles (cinco de ellos de 1 a 3 kms.) en forma de plano inclinado, para lo que el esfuerzo constructor se ejemplifica con lo que se conoce como la "encarrilá", en cuanto se contrataron hasta ocho mil trabajadores que durante tres años conmovieron el 'valle payariego', con todo lo que supuso de construcción en paralelo de poblados, nuevos accesos y apartaderos en la vertiente norte de la Cordillera. Todo este esfuerzo pondría en marcha un modo de transporte alternativo al del camino y ahora carretera N-634 por el puerto de Pajares. Primero, con tracción desde 1884 a 1925. Después, con tracción eléctrica y diésel para resolver la congestión de tráficos, que llegaron a su umbral máximo durante la Primera Guerra Mundial y los primeros años del decenio de 1950.

Las mejoras en la circulación han sido continuas, pero todavía hoy, con trenes Alvia, la distancia en tiempo de León-Gijón es de 2,50 horas, por las dificultades en este tramo de montaña así como por la velocidad lenta en los tramos urbanos desde Pola de Lena a Gijón. Mientras que la distancia por autobús y autopista entre León-Gijón se encuentra en 2 horas, estando a la espera de que la variante de Pajares o nuevo tramo ferroviario — con dos túneles paralelos de $25 \mathrm{kms}$., más otros túneles y viaductos-desde Pola de Gordón a Campomanes por el valle del Huerna, realice el mismo trayecto en la mitad de tiempo, circulando además trenes de mercancías en ancho ibérico. De ello resulta, que rampa y variante, han sido los proyectos más ambiciosos de la infraestructura ferroviaria española.

En segundo término, el ferrocarril por la rampa de Pajares ha servido a la comunicación entre las dos regiones de Asturias (estaciones de fin de recorrido en Avilés y Gijón, sin conexiones a la red) y de la Meseta (estación de tránsito en León, donde conecta a la línea Palencia-Monforte de Lemos y a la red nacional). A su vez, la línea León-Gijón ha servido, sin apenas competitividad durante su primer siglo de existencia, de comunicación y acceso a las localidades de la Montaña Central leonesa. Pero, con mucho, ha servido al abastecimiento energético en España procedente de los carbones asturianos y, cuando este transporte estaba en su mayor apogeo en los años 1950 lo completará también el abastecimiento de bobinas de acero procedente de la siderurgia asturiana, así como otros productos en sentido bidireccional, pero la mayor parte de la carga ha sido unidireccional, lo que produjo graves problemas de servicio y elevado coste en la línea.
En tercer término, este eje ferroviario ha sido un factor esencial del desenclavamiento de la región asturiana, en cuanto que ha fortalecido y puesto las bases del desarrollo urbano e industrial de la Asturias Central, junto a los puertos de Gijón y Avilés y la red ferroviaria regional de vía estrecha, a la vez que ha tenido una transcendencia local respecto a las localidades y valles de la Montaña central astur-leonesa, como es el caso del desarrollo industrial de La Robla.

El estudio se presenta enriquecido por las múltiples consultas efectuadas por el autor en archivos y bibliotecas, que permiten aportaciones de documentos y fotografías de gran relevancia. Pero su labor no queda en la descripción histórica y gráfica de las fases de construcción y explotación del ferrocarril, sino que recoge reflexiones y valoraciones efectuadas a lo largo de las últimas dos décadas desde su experiencia como director del Centro de Cooperación y Desarrollo Territorial (CeCodet) de la Universidad de Oviedo. De ahí el interés que muestran los últimos apartados del volumen referidos a las alternativas inmediatas al futuro de la rampa, una vez que la variante de Pajares entre en servicio, sumando en ella la explotación ferroviaria del transporte de mercancías, hecho transcendente y novedoso en el sistema ferroviario español al sumar dos anchos de vía y dos tipos de tráficos.

De ahí que las valoraciones del profesor Fermín Rodríguez cobren más sentido en cuanto a los nuevos usos de la rampa, que, a la vista de lo ocurrido en otros tramos en desuso en la red ferroviaria española, tienen aún mayor relevancia. $\mathrm{La}$ "propuesta de clasificación de la rampa de $\mathrm{Pa}$ jares como de primera categoría patrimonial", sea Patrimonio de la Humanidad o sea Bien de Interés Cultural, la defiende el autor por lo que supone la historia de este paso ferroviario, ligado como está a la modernización de Asturias y su tejido productivo, a la vez que un recurso territorial de gran valor por los paisajes y hábitats que atraviesa. Por ello, un nuevo destino de la rampa sería, además de trayecto de pruebas de material de la red ferroviaria, permitir la circulación de trenes con vocación turística, máxime si se recupera el "tren de época" en el tramo montañoso de la rampa. Sin embargo, propuestas de este tipo deberían ser dirigidas no tanto a las gestoras ADIF o RENFE, sino más bien, fruto de políticas territoriales, a las dos Comunidades Autónomas, combinado con otro tipo de acciones conjuntas en la Cordillera Cantábrica, un espacio para la cooperación. 